\title{
A INTER-RELAÇÃO ESTRUTURAL ENTRE ALGUNS LIVROS DA METAFÍSICA
}

Fernando Augusto da Rocha Rodrigues*

\section{RESUMO}

O objetivo deste artigo é apresentar uma interpretação dos livros G, ZHQ e L da Metafísica de Aristóteles, mostrando que eles podem ser lidos formando um todo argumentativo conectado. Os demais livros da Metafísica serão aqui desconsiderados, pois não se adéquam à interpretação proposta. $\mathrm{O}$ texto começa mostrando que é plausível concentrar-se em alguns livros dessa obra de Aristóteles e deixar outros de lado. Para fazê-lo, recorre-se a alguns scholars de Aristóteles, começando por C. A. Brandis. Em seguida, o artigo desenvolve uma interpretação do livro $\mathrm{G}$, afirmando que o modelo de ciência aí apresentado requer uma análise do conceito de substância. Dado que há diferentes tipos de substâncias, distinguidos nos capítulos 1 e 6 do livro L, o artigo dedica-se a esse livro e mantém que essa distinção é necessária a fim de se dar uma resposta apropriada à questão da substância. Os livros ZHQ, por sua vez, fornecem uma análise detalhada de um dos conceitos de substância distinguidos em L. Essa leitura dos cinco livros mencionados mostra, assim, que eles podem ser lidos como formando uma unidade.

Palavras-chave: Metafísica. Substância. Aristóteles. Livro G.

\begin{abstract}
This aim of this paper is to provide an interpretation of books G, ZHQ and L of Aristotle's Metaphysics, showing that they can be read as a connected argumentative whole. The other books of Metaphysics will be

* Doutor em Filosofia pela Universität Konstanz. Professor do Departamento de Filosofia e do Programa de Pós-Graduação em Filosofia da UFRJ.

E-mail: farr@uol.com.br
\end{abstract}


here disregarded, since they do not fit in the advanced interpretation. The text starts out by showing that it is plausible to focus on some books of this work by Aristotle, while putting others aside. In order to show this, the author resorts to some traditional scholars of Aristotle, beginning with C. A. Brandis. After that the paper develops an interpretation of book G, maintaining that the model of science put forward in that book requires an analysis of the concept of substance. Since there are different types of substance, which are distinguished in chapters 1 and 6 of book L, the paper addresses this book and holds that this distinction is required in order to give an appropriate answer to the question of substance. Books ZHQ, on the other hand, provide a thorough analysis of one of the concepts of substance distinguished in L. This reading of the five mentioned books shows, therefore, that they can be read as forming a unity.

Keywords: Metaphysics. Substance. Aristotle. Book G.

O presente texto consiste de indicações para uma interpretação de alguns livros da Metafísica de Aristóteles, mostrando como esses livros formam um todo argumentativo. Proponho uma leitura da obra que, partindo do livro $\Gamma$, mostre que $\Lambda$ pode ser lido como seguindo-se diretamente de $\Gamma$ e que o grupo $\mathrm{ZH} \Theta$ seria um desenvolvimento da primeira parte de $\Lambda$. Com relação aos demais livros, serão aqui desconsiderados, pois não contribuiriam para essa estrutura. O que permite que se destaquem alguns livros da Metafísica e se desconsiderem outros é exatamente o fato de essa obra não formar um todo unitário.

Com vistas a ressaltar essa ausência de unidade, farei, antes de abordar propriamente a articulação entre os livros indicados, algumas observações sobre a mudança que a história da interpretação da Metafisica sofreu a partir de alguns comentadores do século XIX. Desses estudos resultou que, de modo hoje incontestável pela maioria dos estudiosos de Aristóteles, o texto da Metafisica é um torso ${ }^{1}$ incompleto, sendo que algumas

${ }^{1}$ A expressão "torso", usada por alguns comentadores alemães da Metafísica no século XIX para caracterizar a estrutura da obra, foi importada para a língua alemã do italiano. A palavra está em uso em alemão desde a metade do século XVIII no contexto da 
de suas partes estariam soltas desse torso. Essa compreensão da Metafísica como um torso legitima, então, a proposta de se fazer uma interpretação da obra concentrando-se em algumas partes e desconsiderando-se outras.

Uma das partes que, para muitos, estaria separada do resto, formando um tratado à parte, é o livro $\Lambda$. Além disso, para uma grande quantidade de intérpretes, o livro $\Gamma$ comporia um todo juntamente com os livros A e B. Se a interpretação proposta em meu texto pode, por um lado, apoiar-se em comentadores para recortar alguns livros da Metafísica, organizando-os em uma certa disposição, ela, por outro lado, não encontra apoio em muitos deles para separar $\Gamma$ do grupo $\mathrm{AB}$ nem para considerar $\Lambda$ como não sendo um tratado independente dos demais livros.

Para fazer frente a essas tendências de interpretação dos livros $\Lambda$ e $\Gamma$, no que toca a suas relações com os demais textos da obra, seguirei, após as observações sobre a virada de interpretação sofrida pela Metafisica no século XIX, o seguinte percurso. Indicarei, em primeiro lugar, que essa leitura do livro $\Lambda$ não é unânime e alguns intérpretes, como será mostrado, voltam a tentar reintegrá-lo no todo da Metafísica. Em segundo lugar, indicarei como $\Gamma$ pode ser destacado do grupo $\mathrm{AB}$, indicando que os elos explícitos e implícitos que sugerem a conexão de $\mathrm{AB}$, por um lado, e $\Gamma$, por outro, podem ser descartados. Enfim, apresentarei, em linhas gerais, a interpretação sugerida por mim acima, inter-relacionando os livros $\Gamma, \Lambda$

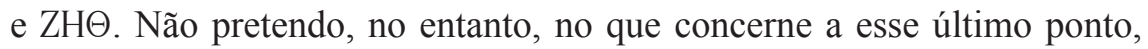
apresentar algo para além de um texto programático.

\section{I}

Desde meados do século XIX, parece consensual, entre a maioria dos pesquisadores que se dedicam à Metafisica de Aristóteles, que os quatorze livros que compõem essa obra não formam um todo coerente. Como é bem sabido, o agrupamento desses quatorze escritos em uma única obra não foi realizado pelo autor, e o título a ela consagrado ( Tà

linguagem artística para designar "o fragmento de uma obra de escultura, sobretudo o tronco de uma figura humana da qual a cabeça e os membros estão decepados" (GRIMM, J.; GRIMM, W., 1838, v. 21, p. 896, verbete: Torso). 


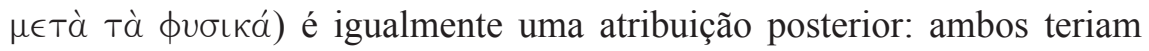
sido resultado do trabalho de Andrônico de Rhodes, que reuniu os textos em uma obra sob a assinatura do filósofo grego ${ }^{2}$. As realizações do editor não se limitam, entretanto, a uma organização externa dos textos; subrepticiamente, elas sugerem a ideia de que a obra editada forma um todo unitário $^{3}$. Uma leitura da Metafísica, ainda que não aprofundada, sugere,

${ }^{2}$ Diferentemente do que ocorreu com a obra de Platão, a transmissão dos escritos de Aristóteles é marcada por uma lacuna no período helenístico. Da morte de Teofrasto (287 a.C.) à época do político romano Sulla ( 136-78 a.C.), encontram-se muito poucas referências aos escritos de Aristóteles, sendo que as que ocorrem não correspondem a textos que compõem o que hoje se conhece como Corpus Aristotelicum. Apesar de Estrabão e Plutarco, em suas narrativas sobre a transmissão dos textos de Aristóteles e Teofrasto, mencionarem, o primeiro, uma edição organizada por Apellicon (Geografia, XIII, 1, 54) e o segundo, uma organização dos textos feita por Tyrannio (Vidas, vida de Sulla, 26), é muito possível que nenhuma dessas duas edições tenha de fato existido e que a edição de Andrônico, na época de Sulla, tenha sido a primeira. A edição de Andrônico é referida em diversas fontes na Antiguidade. Uma lista das referências, que incluem os nomes de Estrabão, Galenus, Aullus Gellius, Alexandre de Afrodisia, encontra-se em I. Düring (1957, 413ss.).

${ }^{3}$ Há, pelo menos, duas maneiras possíveis de se interpretar o título da obra, tà $\mu \in T \grave{a}$

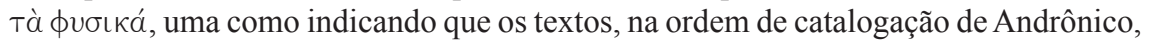
viriam após os textos físicos, outra com a tese de que os assuntos tratados nos textos da Metafísica seriam de um conteúdo mais elevado do que os tratados nos escritos físicos. Sobre uma discussão acerca dessas duas interpretações, ver H. Reiner (1954), bem como J. Owens (1951, 73s.).

Como quer que se interprete o sentido de $\mu \in \tau a ́$, no título da obra, parece ser aceito que Andrônico, com sua edição, pretendeu não apenas reunir textos atribuídos a Aristóteles de modo a colocá-los uns ao lado dos outros, mas antes dar um aspecto sistemático ao todo da obra. Um testemunho dessa intenção de Andrônico encontra-se em Porfírio, quando este, na introdução biográfica à organização dos textos de seu mestre Plotino

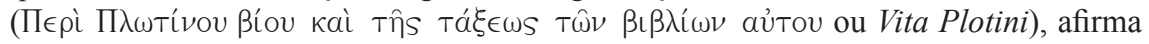
que pretende fazer com a obra de Plotino o que Andrônico fez com a de Aristóteles:

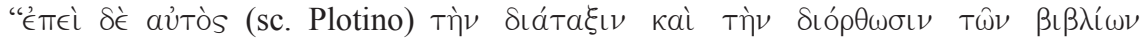

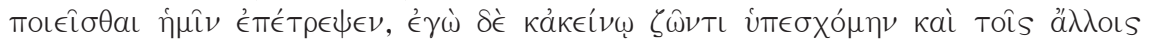

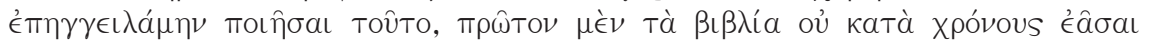

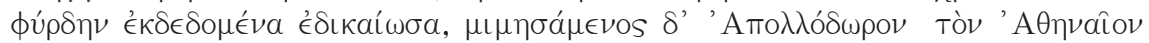

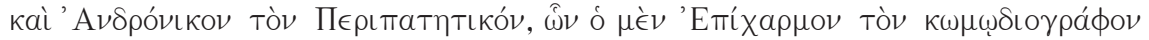

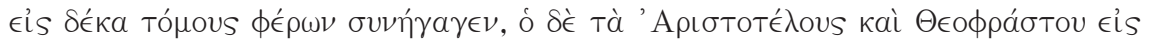

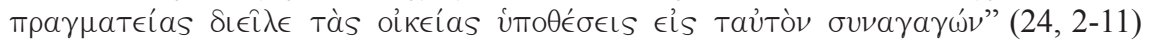
(Dado que ele (sc. Plotino) confiou-nos fazer a ordenação e correção dos livros (= dos 
no entanto, várias dificuldades para se determinar como os seus quatorze livros poderiam estar organizados entre si de modo a produzir uma obra com um tema que se desenvolve organizadamente ao longo de seus textos. Incongruências ${ }^{4}$, duplicações de passagens ${ }^{5}$, visíveis inserções de textos que, muitas vezes, tratam de temas diversos do suposto objeto da Metafísica $^{6}$, fazem com que uma das tarefas com que se depara o intérprete dessa obra seja a de determinar sua estrutura textual, excluindo, se for o caso, textos que nada tenham a ver com essa estrutura. É certamente possível identificar alguns grupos estruturais que não se relacionam entre si. Um intérprete da Metafísica não pode, desse modo, lidar com o texto como faria, para mencionar um exemplo de uma situação evidentemente oposta, um intérprete das Méditations Métaphysiques de Descartes. Aqui, ao contrário da Metafísica, trata-se de uma obra que foi pensada pelo autor como um sistema, cujas partes estão todas organizadas de modo a contribuir para a ideia central do texto ${ }^{7}$.

rolos de papiro) e que eu tanto prometi a ele, quando ele era vivo, quanto anunciei aos outros fazer isso, então eu julguei correto não permitir que os livros ficassem deixados confusamente, na ordem em que foram escritos (катà xpóvous), lembrando-me do ateniense Apolodoro e do peripatético Andrônico, dos quais um, conduzindo a dez partes, reuniu o comediógrafo Epicarmo (= as obras do comediógrafo), o outro (sc. Andrônico) separou as obras de Aristóteles e Teofrasto em pragmateîai, reunindo os

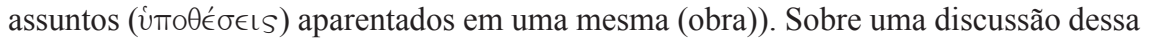
passagem, ver I. Düring (1966, p. 41).

${ }^{4}$ Um exemplo de incongruência pode ser visto no livro Z, em que Aristóteles afirma (1) que a substância não pode ser universal (1038b8s.), (2a) que o universal é o que convém a vários (1038b12), (2b) que a forma é o que é comum a vários indivíduos (1034a7s.) e (3) que a forma é a substância (1032b1s.; 1033b17s.; 1037a29s.; 1041b8s.). A partir de (1), o universal não é substância; a partir de (2a) e (2b), a forma é universal, pois convém a vários; e, a partir de (3), a forma é substância. Essas afirmações gerariam, portanto, uma inconsistência no texto.

${ }^{5}$ Citem-se, como exemplos, as repetições, ainda que com variações, de A9 990b2991b8 em M4 1078b34-1079b3 e M5 1079b12-1080a8 e de passagens de B em K1-2, de Г1-2 em K3-4, de Г3-4 em K5-6 (sendo que resumos de Г5-8 também são encontrados nesses mesmos capítulos de K), de E1 em K7.

${ }^{6}$ Um exemplo de inserção é a discussão sobre os dois sentidos de "ser conhecido", para nós e por natureza, interpolada em Z3 (1029b3-12).

${ }^{7}$ Uma excelente discussão detalhada sobre a natureza do texto da Metafísica encontrase em J. Owens (1951, 69ss.). 
Dentre os primeiros a colocarem a questão sobre a estrutura da Metafisica no século XIX, está Christian A. Brandis ${ }^{8}$. Em seu artigo "Über die Metaphysik des Aristoteles", ele afirma explicitamente a inexistência de um todo unitário na Metafísica e sugere que se deva separar, nessa obra o que pertenceria a diferentes projetos de Aristóteles:

É visível, creio, quão pouco razoável é a atual ordenação dos livros metafísicos de Aristóteles; mas também é visível que seria precário substituir essa ordenação dos livros por uma melhor, a menos que possuíssemos neles não partes integrantes de um todo, mas sim elos espalhados e individualizados que teriam sido elaborados em épocas diferentes, de acordo com diferentes planos, nenhum dos quais possivelmente tenha sido alguma vez desenvolvido totalmente por Aristóteles. Nas tentativas de uma melhor ordenação ter-se-ia, pelo menos, de evitar cuidadosamente a ilusão enganadora de que os livros pertençam uns aos outros de modo perpassante e de separar exatamente o que pertence aos diferentes projetos $(1834,86 \mathrm{~s}$.)

Sua sugestão é a de que se estruturem os livros da Metafísica em quatro linhas básicas (ibidem, p. 87): (1) inicialmente, os livros АВГЕZН $\Theta$ formariam uma unidade, sendo que o livro $\Lambda$, por não se seguir diretamente de $\Theta$, talvez possa ser a este unido por meio do livro I, que serviria para preencher essa lacuna; (2) os livros M e N formariam uma segunda linha; (3) em seguida, viria o livro K (capítulos 1-8, que resumiriam os livros B, $\Gamma$ e E), que talvez pudesse conectar-se a A, pertencendo, desse modo, $\mathrm{A}$ também a essa terceira linha; (4) a quarta linha seria, por sua vez, composta por $\Delta$. O livro a seria, no máximo, um apêndice, comparável aos spuria platônicos.

$\mathrm{O}$ artigo de Brandis serviu para marcar a passagem para uma nova maneira de se interpretar a Metafísica. A ideia de que essa obra formaria um todo unitário passou a ser de difícil sustentação. A posição de Brandis

\footnotetext{
${ }^{8}$ Antes de C. Brandis, Franz N. Titze e Johann C. Glaser já haviam chamado atenção para o fato de a Metafísica não formar uma obra unitária. Estruturavam os seus quatorze livros de modo a formarem duas obras diferentes. Uma breve discussão sobre esses dois intérpretes encontra-se em W. Jaeger (1912, 4ss.).
} 
de que não se pode mais falar de um todo unitário na Metafísica é assumida Hermann Bonitz e pelo historiador da filosofia grega Eduard Zeller. Este último, ao referir-se à Metafísica, afirma: "E tanto mais importante é o escrito sobre a filosofia primeira, um torso com o qual, em nossa Metafísica, um grande número de partes ulteriores, algumas autênticas, outras inautênticas, está externamente conectado" (1844, p. 80).

Hoje em dia os dois pesquisadores que são sempre mencionados em conexão com esse problema da estrutura não unitária da Metafísica são Paul Natorp e Werner Jaeger. Ambos dedicaram-se intensivamente à questão sobre a estrutura dessa obra. $\mathrm{O}$ artigo de Natorp "Thema und Disposition der aristotelischen Metaphysik" e as obras de Jaeger Studien zur Entstehungsgeschichte der Metaphysik des Aristoteles e Aristoteles - Grundlegung einer Geschichte seiner Entwicklung (capítulos 3 e 4) pretendem mostrar, por diferentes caminhos, por que a Metafísica que chegou até nós não pode formar um todo coerente. O primeiro tenta provar que algumas passagens são apócrifas, enquanto o segundo apóiase antes no desenvolvimento do pensamento aristotélico para apontar as inconsistências da Metafisica; na última das obras mencionadas acima, Jaeger também reconhece a existência de passagens apócrifas.

Desde então, a questão sobre a estrutura da Metafísica não ficou mais esquecida. Deparamo-nos com uma quantidade de publicações sobre o tema. Em geral, no entanto, as interpretações parecem manter que o livro $\Gamma$ segue-se do grupo $\mathrm{AB}$ e que o livro $\Lambda$ seria, antes, um tratado à parte. Com relação a $\Lambda$, o próprio $\mathrm{W}$. Jaeger, por exemplo, em acordo com H. Bonitz, mantém que " $\Lambda$ permanece (...) também para nós, como para Bonitz, uma preleção individual independente para a constituição de uma filosofia fundamental" (1912, p. 127). D. Ross, por sua vez, na introdução a seu comentário à Metafísica, afirma que "a unidade de $\mathrm{AB} Г$ está assegurada" (1924, v. 1, xvii) e considera que $\Lambda$ "tem toda a aparência de uma obra separada. Ele se apresenta em sua primeira frase como uma discussão sobre a substância sem referência ao fato de que ZH já trataram de modo bem abrangente desse assunto" (ibidem, xxviii).

\footnotetext{
${ }^{9}$ Natorp serve-se igualmente da metáfora do torso: "Temos de lidar com um torso e, o que é pior, com um torso que foi falsamente restaurado" (1888, p. 38).
} 
Se comentadores significativos da Metafísica tendiam a considerar $\Lambda$ como um tratado à parte. Mais recentemente, no entanto, há alguns intérpretes isolados que buscam reavaliar o local que o livro $\Lambda$ e a teologia ocupam na Metafísica e aqui eu começo a apresentar o item anunciado acima de que é possível considerar esse livro como compondo uma unidade com alguns outros textos da Metafísica. Um primeiro intérprete a reinterpretar o valor posicional do livro $\Lambda$ é G. Patzig. Em seu artigo "Theologie und Ontologie in der 'Metaphysik' des Aristoteles", o autor parte do conhecido problema presente no livro E1 acerca de uma possível inconsistência entre uma ciência universal, que estudaria todos os entes, e uma específica de um ente mais eminente, a teologia. O problema surge, pois Aristóteles parece afirmar que a teologia seria uma ciência universal. O próprio Aristóteles dá-se conta, de resto, disso no passo 1026a23ss. Uma ciência do objeto que é imóvel e separado da matéria é uma ciência de um ente específico e não uma ciência universal, pois não abordaria nem os entes imóveis não separados da matéria, nem os entes móveis não separados da matéria. A ciência do ente enquanto ente, ao contrário, seria uma ciência universal, tendo por tema de investigação o que concerne a todo e qualquer ente. O primeiro tipo de ciência seria a teologia (uma ciência específica); o segundo, a ontologia (uma ciência universal) ${ }^{10}$. O problema surge em E1 (e K7), pois Aristóteles identifica esses dois modelos de ciência.

Desde o século XIX, esse problema foi detectado como insolúvel com base no texto aristotélico, tal como este texto se encontra. Propunhamse, antes, explicações externas para esclarecer por que teria ocorrido essa inconsistência no texto de Aristóteles. Patzig examina e rejeita duas explicações, a de Natorp e a de Jaeger, que consideram, respectivamente, a passagem como apócrifa e como pertencente a uma época inicial do desenvolvimento intelectual de Aristóteles. Sua própria solução consiste

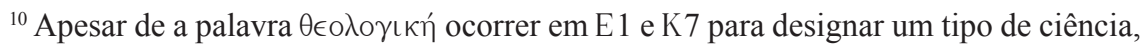
o termo ontologia ou ontológico, evidentemente, não é usado, pois trata-se de uma expressão introduzida apenas no século XVII, tendo ocorrido aparentemente pela primeira vez no Lexicon philosophicum de R. Göckel (Goclenius), de acordo com o verbete Ontologie do Historisches Wörterbuch der Philosophie, (v. 6, p. 1189).
} 
em, a partir da noção aristotélica de paronímia ou - o que, de acordo com

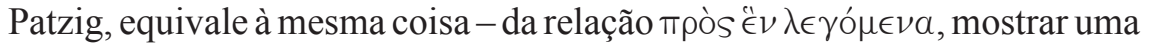
compatibilidade entre a ontologia e a teologia. "A doutrina acerca de Deus, concebida como ela deve ser concebida sob a idéia do rigor conceitual, é ao mesmo tempo a doutrina do ente simplesmente, a ontologia" (1961, p. 195), pois "Deus, dentre todas as substâncias é a primeira substância, a

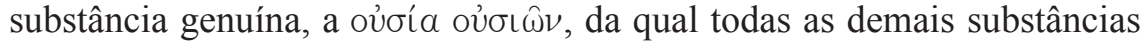
têm, por assim dizer, de tomar emprestado seu ser e pela qual essas outras são preservadas no ser" (ibidem, p. 126). Para sustentar essa interpretação de E1, Patzig volta-se para uma análise do livro $\Lambda$. Aplicando, mais uma vez, a noção de paronímia, o primeiro motor seria o primeiro de que as outras coisas dependeriam. O tratamento dispensado pelos cinco primeiros capítulos de $\Lambda$ às substâncias naturais serve tão somente para remetê-las ao primeiro motor (ibidem, p. 198). A tese de Patzig depende, no entanto, de uma interpretação peculiar da noção de paronímia, uma interpretação que, pelo menos no caso dos vários sentidos do "é", acaba comprometendo-se com uma determinada noção do ente divino.

Um segundo exemplo de reabilitação do livro $\Lambda$, como tendo um papel proeminente na Metafísica, encontra-se em C. Kahn. No texto, "On the Intended Interpretation of Aristotle's Metaphysics", é defendida a posição usual de que $\Lambda$ é um texto inicial da carreira de Aristóteles. A primeira parte desse livro (capítulos 1-5), sobre as substâncias naturais, é uma preparação para a segunda parte (capítulos 6-10), sobre a substância imutável. Aquela foi desenvolvida em $\mathrm{ZH} \Theta$, que, talvez, seriam uma preparação para um desenvolvimento da segunda parte do livro $\Lambda$ (1985, p. 323). Os livros do grupo $\mathrm{ZH \Theta}$ apresentam a substância como forma (Z) e, em seguida, como évé $\gamma \gamma \in \iota \alpha(\Theta)$. Essas concepções da noção de substância sugerem, de acordo com Kahn (ibidem, p. 336), a indicação para um movimento das substâncias investigadas nesses livros em direção à substância divina. Além disso, ele não exclui a hipótese de, não apenas $\Lambda$, mas também o grupo $\mathrm{ZH} \Theta$ serem anteriores aos grupos $\mathrm{AB}$ e $\Gamma \mathrm{E}$, pois $\mathrm{ZH} \Theta$ não fazem referência nem à ciência das causas, nem à ciência do ente enquanto ente (ibidem, p. 336). Além disso, com relação à cronologia relativa entre os grupos $\mathrm{AB}$ e $\Gamma \mathrm{E}$, o primeiro seria anterior ao segundo por não fazer alusão à ciência do ente enquanto ente (ibidem, p. 337). 
Tanto em Patzig quanto em Kahn, pode-se observar uma tentativa de restabelecer a importância do livro $\Lambda$ para a estrutura do todo da Metafísica. Não se trata, em nenhum dos dois autores, de mostrar filologicamente que Aristóteles considerava o texto de $\Lambda$ como conectado a outros livros, de modo que se poderia estabelecer uma continuidade entre eles como se fossem pensados para estar em uma mesma obra. Trata-se, antes, de mostrar como o tema de $\Lambda$ pode correlacionar-se e melhor explicar o tema de outros livros. Para o presente texto, considero, sobretudo, a interpretação de Kahn como relevante.

\section{III}

Se, com base nos dois autores, pode-se reabilitar o papel de $\Lambda$ para o todo da Metafísica, a relação de continuidade entre os grupos AB, por um lado, e $\Gamma E$, por outro, parece não ser questionada. A admissão dessa relação talvez seja tanto mais justificada pelo fato de $\Gamma$ parecer referirse explícita ou implicitamente a B. Em 1004 a32-34 há duas referências explícitas a B. Ao afirmar que cabe a uma única ciência investigar tanto a substância quanto o que depende da substância, essa passagem de $\Gamma$ diz que está referindo-se a uma das aporias e as aporias foram elencadas no livro B. As duas referências a B, no interior de três linhas, são as seguintes:

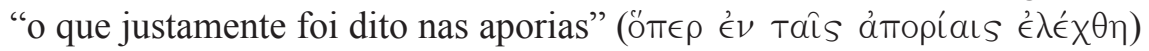

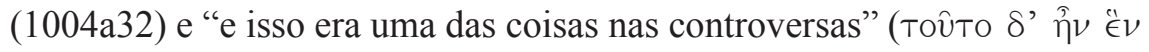

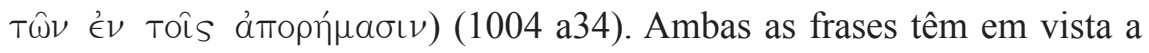
quinta aporia de B, anunciada em 995b18ss. e desenvolvida em 997a25ss. A primeira frase pode ser desconsiderada de pronto, pois ela não aparece em alguns dos manuscritos ${ }^{11}$. A segunda frase, por sua vez, aparece como intercalada. O estabelecimento do texto feito por W. Jaeger indica a ruptura que essa frase introduz ao colocá-la entre parênteses. Sabe-se quão frequente são as expressões e frases introduzidas nos textos aristotélicos para dar unidade a partes aparentemente desconectas. Considerarei aqui,

\footnotetext{
${ }^{11}$ De acordo com o aparato crítico do texto da Metafísica estabelecido por W. Jaeger, o texto presente no Codex Parisinus graecus (E) e no Codex Laurentianus (Ab) omitem a primeira frase.
} 
com base nisso, essa segunda frase como intercalada e não pertencendo originariamente ao texto onde se encontra.

Com isso, fica eliminada a ligação de $\Gamma$ a $\mathrm{B}$ a partir das referências explícitas. Há, no entanto, conforme é apontado, por exemplo, por D. Ross, referências implícitas de $\Gamma$ a B (1924, v. 1, p. xvii). Ross considera que os capítulos 1 e 2 de $\Gamma$ podem ser lidos como uma resposta às aporias 1 e 3 e que o capítulo 3 de $\Gamma$ daria uma resposta à aporia 2. A primeira aporia de $\mathrm{B}$ consiste na pergunta sobre se o estudo das causas pertence a uma ou a muitas ciências (formulada em 995b4s. e desenvolvida em 996a18ss.); a terceira, na pergunta sobre se é uma única ciência que trata de todas as substâncias ou se há várias ciências e, no caso de haver várias, se elas pertencem a um mesmo gênero (formulada em 995b10ss. e desenvolvida em $997 \mathrm{a} 15 \mathrm{ss}$.). A segunda aporia, enfim, concerne à pergunta sobre se a ciência das causas deve considerar os primeiros princípios da substância ou também os princípios gerais da demonstração (formulada em 995b6ss. e desenvolvida em 996b26ss.). A resposta às aporias 1 e 3 estaria no resumo do final do capítulo 2 do livro $\Gamma$ (1005a13ss.) e a resposta à aporia 2 estaria no capítulo 3 (1005a19-b8, sobretudo em b5-8).

Não vou entrar em detalhes na leitura que faz Ross dessa relação. Trata-se aqui, salvo melhor juízo, de uma clara interpretação circular: pressupõe-se haver uma continuidade entre $B$ e $\Gamma$ e identificam-se e interpretam-se passagens de $\Gamma$ à luz da suposição de haver a referida continuidade; em um segundo momento, justifica-se haver a continuidade entre $\mathrm{B}$ e $\Gamma$ exatamente devido à existência das passagens identificadas e interpretadas. Ora, o que se observa aqui é que os trechos selecionados de $\Gamma$, por si mesmos, sem a suposição da continuidade, não precisam ser interpretados como respostas a aporias colocadas em B. Nesse sentido, a continuidade entre $B$ e $\Gamma$ é antes pressuposta de antemão do que provada por passagens do livro $\Gamma$.

Um outro ponto que sugere uma separação entre o grupo $A B$ e o livro $\Gamma$ é o fato de o modelo de ciência estabelecido em $A$, a saber a ciência das primeiras causas e dos primeiros princípios, um modelo para cuja concretização são elencadas as aporias de $\mathrm{B}$, distinguir-se totalmente do modelo de ciência proposto em $\Gamma$, a saber: a ciência do ente enquanto ente. A diferença entre os dois modelos torna-se evidente se se atenta para 
o modelo de universalização defendido em um e outro caso. Ambas as ciências abordariam um objeto universal. No entanto, a universalização em A é obtida por um procedimento de generalização. Busca-se, no caso dos quatro tipos de causas, chegar a causas cada vez mais gerais. A ciência do ente enquanto ente, por outro lado, busca chegar a características universais de todo e qualquer ente por meio de um procedimento de formalização. Um procedimento de formalização consiste justamente em se substituir um elemento conteudístico de uma estrutura por uma variável e se perguntar que condições algo deve preencher para ocupar o lugar da variável. Esses dois procedimentos, totalmente distintos um do outro, para se chegar ao universal, mostram que $\mathrm{A}$ e $\Gamma$ apresentam modelos de ciência incompatíveis. O fato de, além disso, B claramente apresentar questões que a ciência proposta em A deveria tentar responder indica que B seguese naturalmente de $\mathrm{A}$, indicando o que à ciência das primeiras causas e dos primeiros princípios cumpre pesquisar. Desse modo, respostas a essas perguntas não poderiam encontrar-se em um texto, a saber: $\Gamma$, em que o modelo de ciência apresentado difere tão fortemente do de A.

Para se obter uma melhor noção da diferença entre os procedimentos de formalização e generalização, pode-se remontar ao $§ 13$ de Ideen zu einer reinen Phänomenologie und phänomenologischen Philosophie de E. Husserl. Considere-se o seguinte exemplo de formalização. Se se parte do enunciado "Mikko é inteligente", pode-se substituir o termo "Mikko" por uma variável, digamos "S", e perguntar que características um termo deve ter para que possa ocorrer no lugar dessa variável. Isto é: dada a estrutura "S é inteligente", que tipo de termo pode ocorrer no lugar de "S"? A resposta parece clara: para que um termo aí ocorra, ele deve ter a propriedade de referir-se a um objeto que, por sua vez, é classificado por um predicado. $\mathrm{O}$ mesmo pode ser feito com relação ao termo "inteligente", substituindo-o, por exemplo, pela variável "P". Para que um termo conteudístico possa ocorrer no lugar da variável "P", ele deve ter a função de classificar o objeto referido pelo termo que ocorra no lugar de "S". Desse modo, obtém-se a estrutura formal "S é P", com os conceitos formais de termo singular e de predicado. O próprio Aristóteles serve-se do procedimento de formalização em seus escritos lógicos, quando, por exemplo, substitui os termos de um enunciado concreto pelas letras gregas $\mathrm{A}, \mathrm{B}$ ou $\Gamma$. Já o procedimento 
de generalização permite que se obtenha um termo conteudístico mais elevado, i.e. com maior extensão e menor intensão do que o termo de onde se partiu. Dado o conceito de cão, por exemplo, podem-se deixar de lado algumas marcas conteudísticas desse conceito e preservar outras, também conteudísticas, chegando-se, digamos, ao conceito de mamífero. Podem-se, de novo, partindo do conceito de mamífero, eliminar algumas de suas marcas, obtendo-se o conceito de animal, e assim por diante. O ponto de partida e o de chegada da generalização consistem de conceitos conteudísticos, só que conceitos, a cada vez, com menor conteúdo e com um maior âmbito de aplicação.

Que a ciência universal do livro $\Gamma$ sirva-se, com base na expressão "ente enquanto ente", de um procedimento de formalização ficará claro mais abaixo. Que a ciência do livro A, por sua vez, busque alcançar elementos universais com base na generalização pode ser visto a partir de Physica II, 3, 195a32ss., onde Aristóteles, ao referir-se a uma das causas de uma estátua, diz que, por um lado, ela é Policleto, por outro, escultor, por outro, homem, por outro, animal. Essa relação que os termos Policteto, escultor, homem e animal mantêm entre si deixa-se claramente caracterizar como uma relação de generalização. Sendo assim, a ciência das quatro causas chega a algo cada vez mais universal, não formalizando, mas generalizando. As primeiras causas e princípios são ganhos por generalização.

É verdade que o livro $\Gamma$ também se refere a princípios e causas. Logo no início de $\Gamma$, no passo 1003a26, lê-se: "Dado que buscamos os

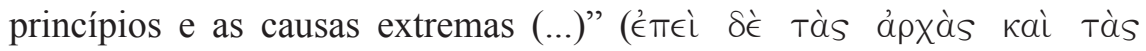

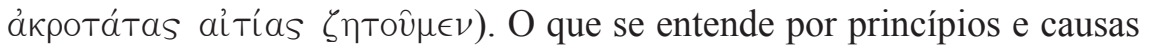
nesse contexto é, contudo, bem diferente do sentido de princípios e causas quando essa expressão ocorre em $\mathrm{A}$. Em $\Gamma$, os termos referem-se àquelas condições que devem ser preenchidas para que algo seja um ente e não aos quatro tipos de princípios e causas últimos obtidos por generalização. Esses princípios e causas são explicitados em $\Gamma$, a partir do capítulo 3 , tratandose do princípio da não contradição e do princípio do terceiro excluído.

Essas observações excluem a usual leitura que busca conectar $\Gamma$ ao grupo AB. Sendo assim, fica aberta a possibilidade de se tomar $\Gamma$ como pertencendo a um outro agrupamento de livros. É o que tentarei apresentar a seguir. 


\section{IV}

O modelo de ciência a ser desenvolvido em $\Gamma$ visa, como é dito na primeira frase do livro, investigar o ente enquanto ente: "Há uma certa ciência que investiga o ente enquanto ente e o que lhe convém per se"

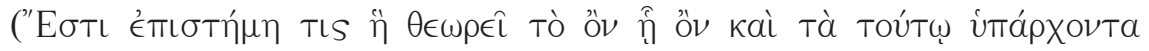
$\kappa a \theta^{\prime}$ aúтó). O que significa ente enquanto ente fica claro se considerarmos expressões de estrutura equivalente, em que o termo ị é utilizado. $\mathrm{Na}$ Ethica Nicomachea, por exemplo, quando, no livro III, Aristóteles aborda

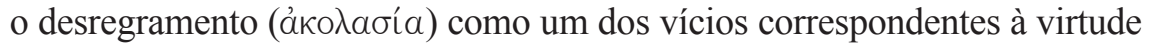
temperança ( $\sigma \omega \phi \rho \circ \sigma u ́ v \eta)$, ele diz que esse vício "pertence [a nós] não

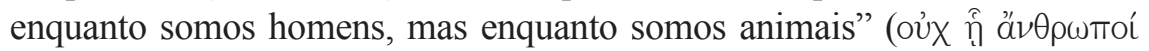

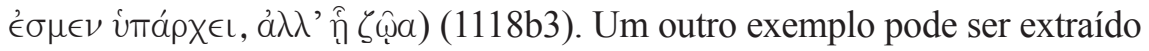
do livro VIII. Aristóteles, no passo 1161b5s., afirma que "enquanto escravo, não há amizade [de um mestre] com relação a ele, mas enquanto homem"

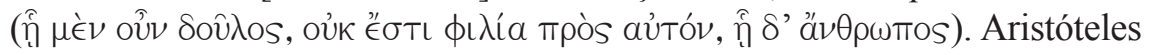
mantém, nesse passo, que o mestre e o escravo são tão diferentes que não pode haver entre eles amizade enquanto um é considerado como escravo e o outro como mestre, mas apenas se são considerados como homens. Esses exemplos mostram que o complemento do ñ indica a perspectiva segundo a qual se considera o antecedente. Nesse sentido, pode-se, por exemplo, considerar um homem da perspectiva de ele ser um animal. Tudo o que se disser do homem sob essa perspectiva vai ter de valer também para todos os animais. Sob essa perspectiva, portanto, não se poderá dizer que o homem é racional, pois esse atributo não lhe convém pelo fato de ele ser animal ${ }^{12}$.

A ciência do ente enquanto ente é a que vai considerar um ente, qualquer que seja, sob a perspectiva de ele ser um ente. Mas o que significa isso? Um ente é tudo aquilo de que se pode dizer "é". Deve-se considerar, então, algo qualquer de que se pode dizer é (por exemplo, um homem, um

\footnotetext{
${ }^{12}$ A expressão "ente enquanto ente" ocorre em Г1, Г2, Г3, E1, E4, K3, K4 e K7. Nos contextos de $\Gamma$ e de K3 e K4, ela designa claramente que o ente é considerado sob a perspectiva de dele se poder dizer "é". Nos contextos de E e de K7, há uma identificação do ente enquanto ente com o ente separado e imóvel. Não discutirei esse conhecido problema do duplo sentido em que a expressão é usada, pois ela afastaria minha discussão do objeto do presente texto.
} 
animal, uma cor, uma altura) e se perguntar o que lhe convém pelo fato de dele se poder dizer "é", i.e. não pelo fato de ele ser um homem ou uma cor, mas pelo fato de ser.

Ora, como "é" se aplica a toda e qualquer coisa, essa ciência dirá respeito a tudo, sendo, portanto, uma ciência universal. A investigação, realizada pela ciência proposta em $\Gamma$, parte de um ente qualquer que seja e o considera sob a perspectiva de dele se poder dizer "é", mas, ao fazer isso, ela estará considerando não apenas aquele ente de onde se partiu, mas, antes, tudo aquilo de que se diz "é". Partindo-se do enunciado "Sócrates é", pergunta-se o que se pode saber acerca de Sócrates pelo mero fato de ele ser. Esse modo de abordar a questão consiste, na verdade, em se substituir "Sócrates", na estrutura "Sócrates é”, por uma variável, de modo a obter-se "x é" e se perguntar o que algo deve preencher para poder ocorrer no lugar de x. Isso é exatamente o procedimento de formalização.

O problema com que se depara Aristóteles nessa investigação está no fato de que o "é" possui diversos sentidos. A repetida afirmação, presente também no início do capítulo 2 de $\Gamma$, de que "ente se diz de

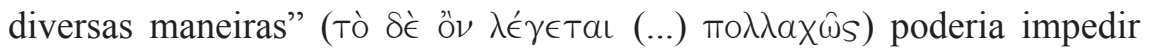
que se chegasse a uma ciência universal, que contemplasse tudo aquilo de que se diz que "é", pois, ainda que se possa dizer "é" de tudo, o "é" teria diferentes sentidos, dependendo daquilo a que se aplica, o que, à primeira vista, poderia acarretar que haveria tantas ciências quantos sentidos há do ser. É conhecida a solução de Aristóteles para o problema. Ela encontra-se na segunda frase do capítulo 2 de $\Gamma$. O ente é dito de diversas maneiras,

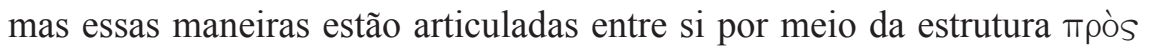
ÉV. Trata-se não de uma relação de homonímia, em que várias coisas seriam chamadas pelo mesmo nome de modo meramente acidental, mas sim de

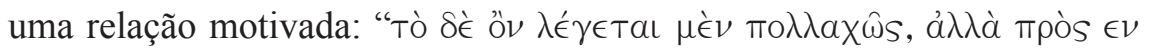

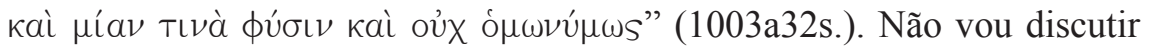
em detalhes o que Aristóteles tem em vista com a expressão прòs Év e nem

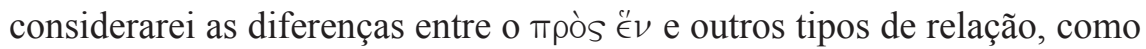
a analogia, a sinonímia, a homonímia, entre outras ${ }^{13}$. Limito-me a indicar

${ }^{13}$ Para uma discussão mais pormenorizada dessas questões, cf. meu texto "Os Sentidos de Ser, a Relação pròs hén e a Estrutura Semântica de Proposições” (RODRIGUES, 1997). 
que a relação mantida entre os vários sentidos de ente é um espelhamento da relação de predicação. Os sentidos distinguidos são, por um lado, as substâncias e, por outro, atributos da substância, como as afecções das substâncias (1003b6ss.). A substância é dita ser no sentido pregnante e as propriedades são ditas ser na medida em que mantêm uma relação com a substância. Desse modo, diz-se, em um sentido pregnante, que Sócrates é e, em um sentido derivado, que o branco de Sócrates é. Este último só é porque Sócrates (que é uma substância) é. Sendo assim, a ciência esboçada no livro $\Gamma$, além de tratar dos princípios que convêm a tudo o que é, o que, a meu ver, é feito a partir do capítulo 3 do livro $\Gamma$, deverá, também responder a duas questões: (1) em que consiste a substância? e (2) que tipo de relação coisas que não são substâncias, sendo antes suas propriedades das mesmas, mantêm com a substância. Essa última questão pode ser respondida a partir, como sugeri acima, da estrutura da predicação. Mas como responder a primeira questão?

O livro $\Lambda$ compõe-se de duas partes, capítulos 1-5, por um lado, e capítulos 6-10, por outro. Tanto o início da primeira parte (1069a30ss.) quanto o início da segunda parte (1071b3ss.) começam apresentando uma classificação das substâncias. Aristóteles distingue três tipos de substâncias: a sensível ou física ( $a i \sigma \theta \eta T \eta ́$ ou $\phi \cup \sigma \iota \kappa \eta ́)$, que, por sua vez, se subdivide em

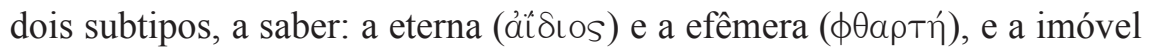
(ảkívๆtos). A sensível ou física é objeto dos capítulos 1-5 e a imóvel, objeto dos capítulos 6-10. Essa divisão das substâncias indica que uma das perguntas a serem respondidas pela ciência apresentada em $\Gamma$, a saber: a pergunta em que consiste a substância?, divide-se, na verdade, em duas perguntas: (1) em que consiste a substância sensível ou física? e (2) em que consiste a substância imóvel? É importante indicar, contudo, que os dois sentidos são, na verdade, duas espécies de um mesmo gênero ${ }^{14}$.

${ }^{14} \mathrm{O}$ gênero da substância parece ser definido por duas características presentes em Z3: a substância é aquilo de que se predica e não é predicada de nada (1029a8s.)

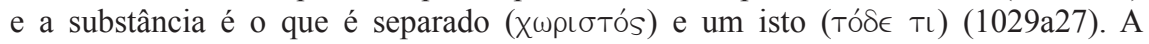

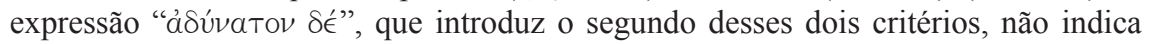
uma substituição, mas uma complementação, do primeiro pelo segundo. 
A resposta à primeira das perguntas está presente, de modo sucinto,

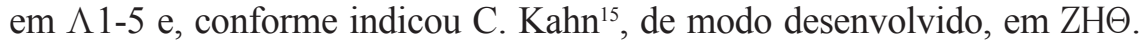
A resposta à segunda está presente em sua forma apenas sucinta, em $\Lambda 6-10$.

$\mathrm{Se}$ as considerações acima se sustentam, pode-se, então, vislumbrar uma organização temático-argumentativa entre os livros $\Gamma, \Lambda$ e $\mathrm{ZH} \Theta$. O primeiro coloca a questão do ente enquanto ente. Essa questão, no entanto, não pode ter apenas uma resposta, pois, como o "é" se diz em diversos sentidos, sendo um pregnante e os demais dependentes do pregnante, é preciso que se diga em que consiste o sentido pregnante e como se dá a relação de dependência dos sentidos não pregnantes com relação ao pregnante. A segunda destas perguntas consistiria em explicar

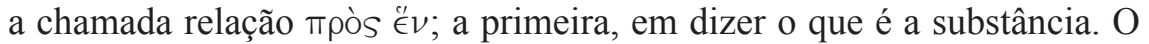
livro $\Lambda$, contudo, mostra que a substância tem vários sentidos, abordando, separadamente, dois deles que, juntos, abarcariam todas as substâncias: a sensível ou física e a imóvel. Essa separação na abordagem indica que a resposta à questão sobre a substância deve também subdividir-se em duas investigações, ainda que haja um elemento em comum aos dois sentidos de substância. A parte de $\Lambda$ que trata da substância sensível ou física, por sua

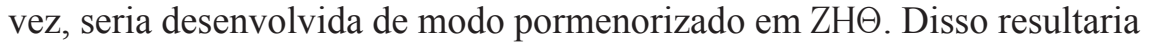
o esquema:

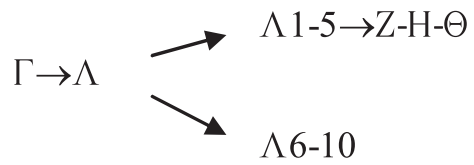

$* * * * *$

O que aqui se apresentou é meramente programático. Trata-se de um primeiro esboço para uma investigação que, para se mostrar mais convincente, exigiria, sobretudo, uma abordagem detalhada do grupo $\mathrm{ZH} \Theta$, mostrando que, particularmente no que toca a $\mathrm{Z}$, não se trata aí de

\footnotetext{
${ }^{15}$ Cf. acima p. 7.
} 
um tratamento da substância em geral, mas da substância sensível ou física. Apesar do caráter esquemático do texto, creio, no entanto, que a interpretação sugerida, correlacionando os mencionados cinco livros da Metafisica e desconsiderando os demais nove livros, possui plausibilidade, podendo indicar, sobretudo para $\Gamma$, um novo valor posicional com relação aos demais livros da obra.

\section{Referências}

ARISTÓTELES: Ethica Nicomachea, org. p. L. Bywater, Oxford Classical Texts, Oxford University Press, Oxford, 1894ํ․ 1988.

ARISTÓTELES: Metaphysica, org. p. W. Jaeger, Oxford Classical Texts, Oxford University Press, Oxford, 1957¹ 1985.

ARISTÓTELES: Physica, org. p. W. D. Ross, Oxford Classical Texts, Oxford University Press, Oxford, 1950¹, 1988.

BONITZ, H. (1871) Aristoteles' Metaphysik, Neubearbeitung der Übersetzung von H. Bonitz mit Einleitung und Kommentar herausgegeben von H. Deidl. Hamburg: Felix Meiner, 1991.

BRANDIS, C. A. (1834) Über die Metaphysik des Aristóteles. Erste Hälfte. In: Abhandlungen der historisch-philosophischen Klasse; Abhandlungen der Königlichen Akademie der Wissenschaften zu Berlin, aus dem Jahre 1834, Berlin: Drückerei der Königlichen Akademie der Wissenschaften, 1836. p. 63-87. DÜRING, I. Aristotle in the Ancient Biographical Tradition. Göteborg: Acta Universitatis Gothoburgensis, 1957.

. Aristoteles - Darstellung und Interpretation seines Denkens. Heidelberg: Carl Winter, 1966.

GRIMM, J.; GRIMM, W (início: 1838). Deutsches Wörterbuch. Munique: Deutscher Taschenbuch Verlag (dtv), 1991. v. 21. (vol. 11, $1^{\mathrm{a}}$ seção, $1^{\mathrm{a}}$ parte, 1935).

HUSSERL, E. (1913) Ideen zu einer reinen Phänomenologie und phänomenologischen Philosophie. Tübingen: Max Niemeyer, 1980.

JAEGER, W. Studien zur Entstehungsgeschichte der Metaphysik des 
Aristoteles. Berlin: Weidmannsche Buchhandlung, 1912. . Aristoteles - Grundlegung einer Geschichte seiner Entwicklung. Berlin: Weidmannsche Buchhandlung, 1923.

KAHN, C. On the intended Interpretation of Aristotle's Metaphysics. In: Aristoteles Werk und Wirkung. WIESNER, J. (Org.). Berlin: Walter de Gruyter, 1985. p. 311-338.

NATORP, P. Thema und Disposition der aristotelischen Metaphysik. In: Philosophische Monatshefte, 1888. p. 37-65; p. 540-574. v. 24.

OWENS, J. (1951) The Doctrine of Being in the Aristotelian 'Metaphysics' - A Study in the Greek Background of Medieval Thought. 3. ed. Toronto: Pontifical Institute of Mediaeval Studies, 1978.

PATZIG, G. Theologie und Ontologie in der "Metaphysik" des Aristoteles. In: Kant-studien, v. 61, p. 185-205, Jan. 1960.

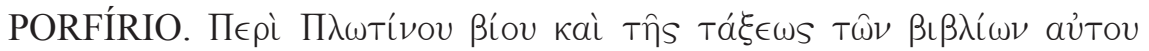
ou Vita Plotini. In: VOLKMAN, R. (Org.). Plotini Enneades, praemisso Porphyrii de vita Plotini deque ordine librorum eius libello, v. 1, Leipzig: Teubner, 1883.

REINER, H. Die Entstehung und ursprüngliche Bedeutung des Namens Metaphysik. In: Zeitschrift für philosophische Forschung, v. 8, p. 210-237. 1954.

RITTER, J.; GRÜNDER, K. Historisches Wörterbuch der Philosophie. Darmstadt: Wissenschaftliche Buchgesellschaft, 1984. v. 6.

RODRIGUES, F. Os Sentidos de Ser, a Relação pròs hén e a Estrutura Semântica de Proposições. O Que Nos Faz Pensar, Rio de Janeiro, v. 1, n. 11, p. 151-173, Mar. 1997.

ROSS, D. Aristotle's Metaphysics. Oxford: Clarendon Press, 1981.

ZELLER,E.(1844-52)DiePhilosophiederGriecheninihrergeschichtlichen Entwicklung. Darmstadt: Wissenschaftliche Buchgesellschaft, 1963. $2^{\mathrm{a}}$ parte, $2^{\mathrm{a}}$ seção.

Data de registro: 10/01/2011

Data de aceite: 16/02/2011 
